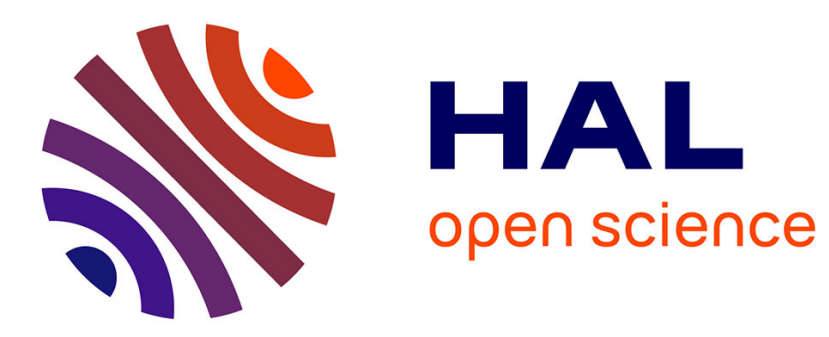

\title{
La blogosphère tunisienne
}

\author{
Timothée Giraud, Marta Severo
}

\section{- To cite this version:}

Timothée Giraud, Marta Severo. La blogosphère tunisienne. Espace Géographique, 2011, 40 (2), pp.190. hal-00676201

\section{HAL Id: hal-00676201 \\ https://hal.science/hal-00676201}

Submitted on 5 Mar 2012

HAL is a multi-disciplinary open access archive for the deposit and dissemination of scientific research documents, whether they are published or not. The documents may come from teaching and research institutions in France or abroad, or from public or private research centers.
L'archive ouverte pluridisciplinaire HAL, est destinée au dépôt et à la diffusion de documents scientifiques de niveau recherche, publiés ou non, émanant des établissements d'enseignement et de recherche français ou étrangers, des laboratoires publics ou privés. 


\section{La blogosphèretunisienne}

\section{Timothée Giraud, Marta Severo}

dansL'Espacegéographique 2/2011 (Tome 40), p. 190. URL :www.cairn.info/revueespace-geographique-2011-2-page-190.htm.

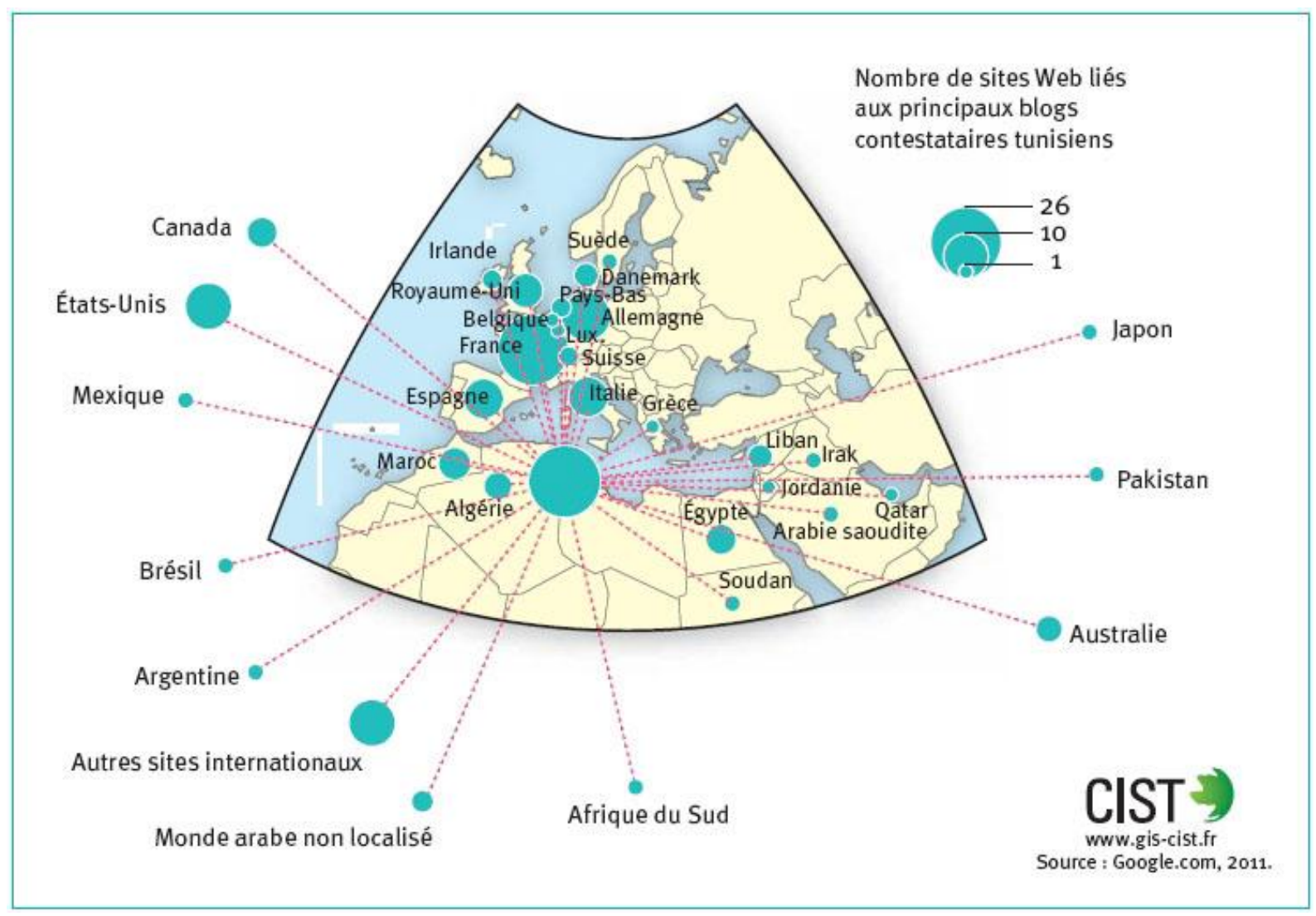

Cettecartographieinstantanée de liens sociaux a étéréalisée par le GIS Collège international des sciences du territoiredans le cadre du projetGeomediaMapper, une plate-formedédiée à l'explorationet à la visualisation de donnéesgéographiques et médiatiques. Dansun premier temps, unequinzaine de sites contestatairestunisiens (blogs, Twitter, Facebook) ontétéidentifiés à partird'une revue de la presseinternationale. Un outilproposé par Google aensuitepermis de recenser les adresses des blogs qui ontintégré, lors des événements de janvier 2011, un lien hypertexte avec ces sites. Enfin, la plupart de cesblogsontétélocalisés par pays, à partir du nom de domaineoud'autresinformationscontenuesdansleurs pages.

La carte met en lumière, outrel'importance des liens internes à la Tunisie, une liaison privilégiée avec l'Europe, surtout avec la France (25), maisaussil'Allemagne (12), l'Italie (8), l'Espagne (8) et le Royaume-Uni (6). Des liens significatifs existent aussi avec les États-Uniset le Canada. En analysantcesblogsoccidentaux, iln'est pas surprenant de constaterque plus de la moitiésontgérés par des personnesoriginaires du Maghreb et qu'ilssontsouventrédigés en langue arabe. 
